\title{
Heart rate variability in left ventricular dysfunction and heart failure: effects and implications of drug treatment
}

\author{
Y S Tuininga, D J van Veldhuisen, J Brouwer, J Haaksma, H J G M Crijns, \\ A J Man in't Veld, K I Lie
}

\begin{abstract}
Objective-To review the importance of heart rate variability analysis in left ventricular dysfunction and heart failure and to assess the effects of drug treatment. In patients with left ventricular dysfunction or heart failure, a low heart rate variability is a strong predictor of a low probability of survival. Because drug treatment in these patients has rapidly changed over the past two decades, the effect of these drugs on heart rate variability needs special attention.

Design-A study of published reports to give an overview of heart rate variability in patients with left ventricular dysfunction or heart failure and how it is affected by drug treatment.

Results-Analysis of heart rate variability provides an easily obtained early marker for progression of disease. It seems to be more closely related to the degree of neurohumoral activation than to haemodynamic variables. Cardiovascular drugs may either stimulate or inhibit the degree of neurohumoral activation, and the effects of pharmacological intervention can be closely monitored with this method.

Conclusions-The analysis of heart rate variability, including spectral analysis, is a novel non-invasive way to obtain potentially useful clinical information in patients with reduced left ventricular function. The effects of drug treatment on heart rate variability are in general consistent with their long-term effects in left ventricular dysfunction and heart failure.
\end{abstract}

(Br Heart f 1994;72:509-513)

Heart rate (HR) and blood pressure are under continuous autonomic control. ${ }^{1}$ In patients with left ventricular (LV) dysfunction and heart failure, changes in autonomic control are often found. ${ }^{2}$ Sympathetic activation, either isolated or during exercise ${ }^{3}$ is associated with the occurrence of ventricular arrhythmias $^{4}$ and reduces the threshold for ventricular fibrillation. ${ }^{5}$ Furthermore, reduced vagal activity has been associated with the occurrence of ventricular fibrillation. ${ }^{67}$
Therefore, the autonomic changes found in patients with LV dysfunction and chronic heart failure can set the stage for sudden cardiac death.

Measurement of $H R$ variability provides a non-invasive method to obtain reliable and reproducible information on autonomic modulation of $\mathrm{HR}^{8}$ and has become an important tool for risk assessment. As the incidence of sudden death is disproportionately high in patients with mild heart failure but a relatively preserved LV function, ${ }^{9}$ it is very important to identify these patients. Obviously, in this group of patients sudden death is particularly devastating. ${ }^{10}$

Measurement of HR variability may also be used to evaluate the effects of drug treatment in these patients. In this review, we discuss the current data on $\mathrm{HR}$ variability in $\mathrm{LV}$ dysfunction and heart failure. Furthermore, the effects of drug interventions on HR variability are considered and implications for clinical use of analysis of HR variability are suggested.

Heart rate variability in left ventricular dysfunction and heart failure

Under physiological conditions, there are periodic fluctuations of HR due to respiration, baroreflexes, and slow variations-for example, temperature regulation. ${ }^{11}$ For measurement of HR variability, basically two methods are used: time domain and frequency domain analysis. ${ }^{81213}$

Early HR variability studies in heart disease $^{14}$ focused on patients with acute myocardial infarction. Variability in HR was shown to be reduced within a few days, ${ }^{1516}$ and this correlated with a poor prognosis. ${ }^{151718}$ It was hypothesised, that impairment of $\mathrm{HR}$ variability might be related to the development of heart failure, as $44 \%$ of patients with a low $H R$ variability (SD of $R R$ intervals $<50 \mathrm{~ms}$ ) were shown to have signs of heart failure, compared with only $8 \%$ of patients with a high HR variability. ${ }^{17}$ Furthermore, neurohumoral activation in the first days after acute myocardial infarction was more pronounced in those with an impaired LV function compared with those with a normal function. ${ }^{19}$

As part of the captopril and thrombolysis study, ${ }^{20}$ we recently showed, that $H R$ variability early after myocardial infarction may 
Figure 1 Absolute changes in measures of $H R$ variability variables $S D$, $r M S S D$, and $p N N 50$ between the period before discharge and three months after a first anterior myocardial infarction in 53 patients no dilation ( $n$ $=25$, and dilation $n=$ 28). rMSSD, root mean square of successive difference; $p N N 50$, the proportion of adjacent $R R$ intervals $>50 \mathrm{~ms}$ different from its preceding interval.

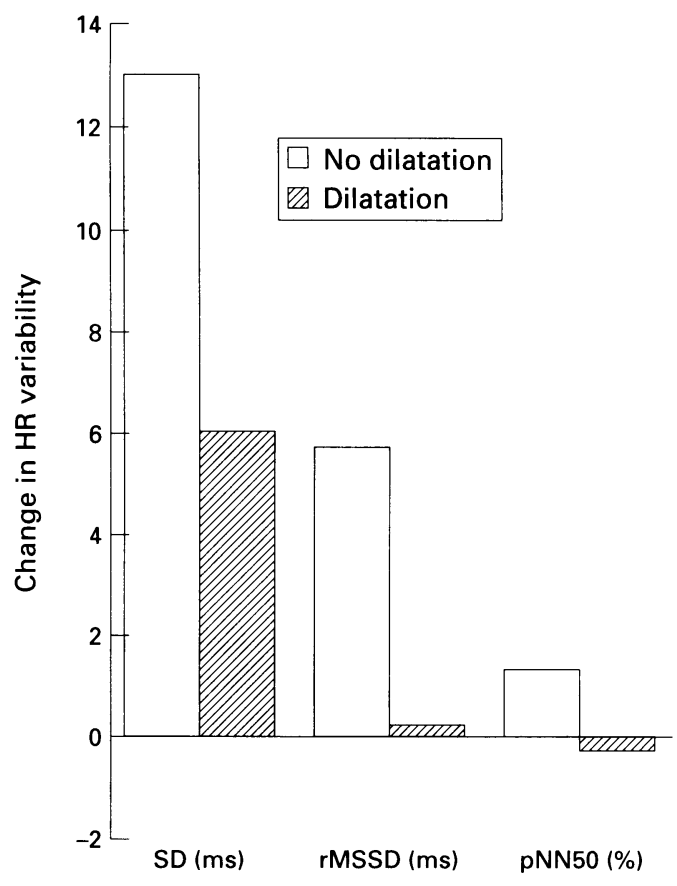

predict subsequent LV dilatation. ${ }^{21}$ Before discharge from hospital, at a time when LV volume was still normal, patients with a low HR variability index had a significantly higher risk for subsequent dilatation compared with those with a high index. ${ }^{21}$ Furthermore, patients who developed an increase in LV end systolic volume after three months showed hardly any improvement in HR variability, whereas in those without LV dilatation HR variability had clearly improved after three months follow up (fig 1). ${ }^{22}$

Among the first to study $\mathrm{HR}$ variability in chronic heart failure were Saul et al, ${ }^{23}$ who showed that patients with advanced heart failure had a considerably reduced HR variability. Casolo and coworkers were able to confirm these findings. ${ }^{24}$ Binkley et al showed that parasympathetic withdrawal is an important component of autonomic imbalance in

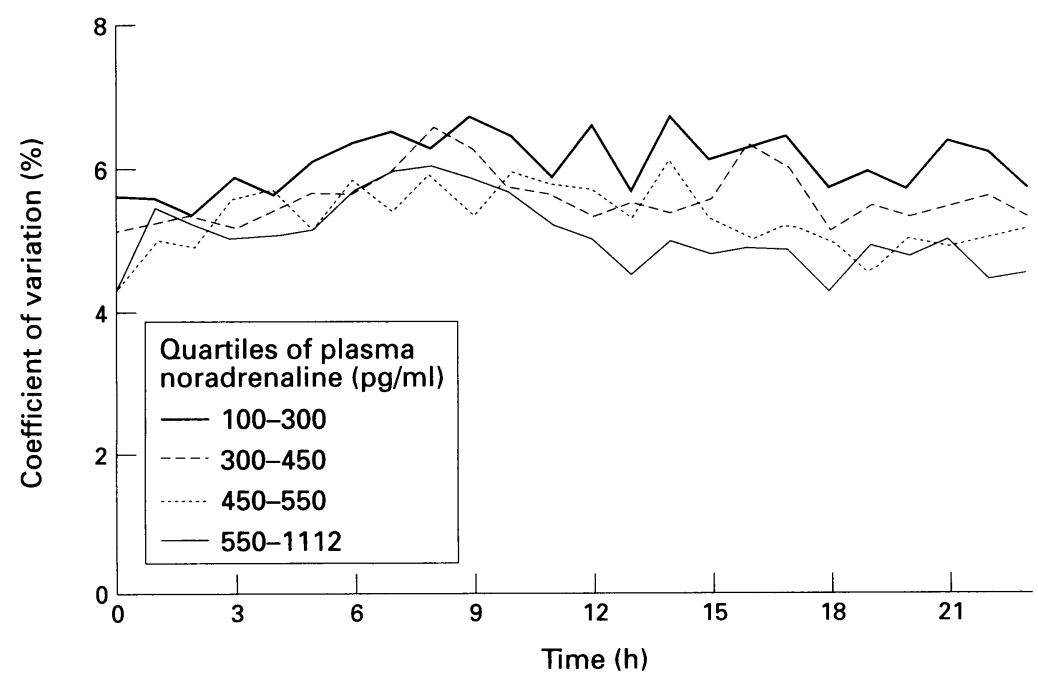

Figure 2 Circadian relation between the four quartiles of plasma noradrenaline concentrations and HR variability, measured as coefficient of variation. High plasma noradrenaline concentrations correlate with low circadian HR variability and vice versa. ${ }^{27}$ chronic heart failure, as sympathetic stimulation alone (by isoprenaline) did not result in the typical pattern of HR variability found in heart failure. ${ }^{25}$ Therefore, probably both sympathetic and parasympathetic components of autonomic control are abnormal in chronic heart failure, and both affect the variability pattern.

To provide information about neurohumoral maladaptation in heart failure it was suggested that impairment of $\mathrm{HR}$ variability should be examined. ${ }^{26}$ We recently studied the relation between neurohumoral activation and $H R$ variability in a large group of patients with chronic heart failure. ${ }^{27} \mathrm{~A}$ negative correlation was found between plasma noradrenaline concentrations and relatively slow fluctuations in $\mathrm{HR}$ variability $(r=-0.30$ to $-0.34, P<0.01$; fig 2 ). Furthermore, a significant positive correlation was found between ejection fraction and more rapidly fluctuating $\mathrm{HR}$ variability parameters $(r=0.30 ; \mathrm{P}<0.05) .{ }^{27}$ Also, we recently discovered that short-term improvement of haemodynamics improved HR variability in patients with severe chronic heart failure, ${ }^{28}$ which underlines the relation between haemodynamic and autonomic function.

Only two studies have so far investigated the predictive value of $H R$ variability in chronic heart failure. ${ }^{29} 30$ Binder et al showed that $H R$ variability was the most powerful predictor of an increased risk of cardiac death in patients on a waiting list for heart transplantation, ${ }^{29}$ and Woo et al found that a reduced $\mathrm{HR}$ variability indicated an increased likelihood of sudden death. ${ }^{30}$

\section{Effects of drug treatment on heart rate variability}

Neurohumoral activation plays an important part in chronic heart failure, and may not be just a marker for the severity of chronic heart failure, but may actually contribute to the progression of disease. ${ }^{31}$ As a consequence, neurohumoral inhibiting agents, particularly angiotensin converting enzyme (ACE) inhibitors ${ }^{32}$ and $\beta$ blockers, ${ }^{33}$ but possibly also digoxin and dopamine agonists, ${ }^{34}$ might have a favourable long-term effect in chronic heart failure. By contrast, drugs that increase neurohumoral activation, such as calcium channel blockers, ${ }^{35}$ inotropic agents, ${ }^{36}$ and probably also some antiarrhythmic drugs, particularly those of class $\mathrm{I},{ }^{37}$ could be expected to have adverse effects on prognosis. ${ }^{38}$ Whether or not these drugs also adversely affect HR variability would therefore be of interest (table). As HR is inversely proportional to HR variability, the most interesting agents would be those that do affect $H R$ variability without effects on $H R$.

\section{ANGIOTENSIN CONVERTING ENZYME} INHIBITORS

The ACE inhibitors have become a cornerstone in the treatment of chronic heart failure. Recent data suggest that the neurohumoral effects may be one of their 
Effects of cardiovascular drugs on neurohumoral activation $H R$ variability, and survival in patients with left ventricular dysfunction or chronic heart failure

\begin{tabular}{llll}
\hline & $\begin{array}{l}\text { Neurohumoral } \\
\text { activation }\end{array}$ & $\begin{array}{l}\text { HR } \\
\text { variability }\end{array}$ & Survival \\
\hline$\beta$ Blockers & $\downarrow$ & $\uparrow$ & $\uparrow$ \\
ACE inhibitors & $\downarrow$ & $\uparrow$ & $\uparrow$ \\
Digoxin & $\downarrow$ & $\uparrow$ & $?$ \\
Dopamine agonists & $\downarrow$ & $\uparrow$ & $?$ \\
Calcium antagonists & $\uparrow /$ & $\uparrow$ & $\downarrow ?$ \\
Diuretics & $\uparrow$ & $?$ & $\downarrow$ \\
Inotrops & $\uparrow$ & $\downarrow$ & $\downarrow$ \\
Class I AAD & $?$ & - & $?$ \\
Class III AAD & $?$ & & \\
\hline AAD, antiarrhythmic drug; & $\uparrow$, increase; $\downarrow$, decrease; \\
一, unchanged; ?, unknown.
\end{tabular}

most important properties. ${ }^{39}$ The favourable effect on survival was most pronounced in patients with the highest degree of neurohumoral activation. ${ }^{40}$ Both captopril $^{41}$ and zofenopril ${ }^{42}$ were found to affect $H R$ variability through an increase in parasympathetic activity in patients with chronic heart failure. By contrast, in normal subjects, ACE inhibition did not affect $H R$ variability. ${ }^{43}$ This effect of ACE inhibitors on HR variability therefore parallels their neurohumoral modulating effects in chronic heart failure as well as their beneficial effect on prognosis.

\section{$\beta$ BLOCKING AGENTS}

$\beta$ Blocking agents may be beneficial in patients with chronic heart failure and their ability to reduce sympathetic activity possibly leads to a favourable long-term effect. ${ }^{3844}$ After myocardial infarction, these drugs increased the vagal component of $H R$ variability. ${ }^{45}$ In patients with chronic heart failure, $\beta$ blockers were reported to restore the autonomic imbalance, as shown by normalisation of HR variability. ${ }^{46}$ The degree by which $\beta$ blockers may influence autonomic control has been suggested to depend on whether these drugs are lipophilic or hydrophilic. ${ }^{6}$ The clinical relevance of these findings, however, remains to be elucidated.

\section{DIGOXIN}

Digoxin has been a controversial drug in many ways. ${ }^{47}$ Recent studies, however, indicate that the drug has a place in the treatment of heart failure. ${ }^{48-50}$ Digoxin increased baroreceptor sensitivity and reduced neurohumoral activation by enhancing vagal activity. ${ }^{345152}$ In patients with chronic heart failure, we have recently shown that digoxin increased vagal activity. ${ }^{53}$ Also, digoxin partly restored the disturbed circadian pattern of $H R$ variability. Even in healthy people, treatment with digoxin notably increased the vagal component of HR variability without effects on the mean RR interval: a $51 \%$ increase in the high frequency component was reported. ${ }^{43}$

DOPAMINERGIC AGENTS

One of the newer neurohumoral modulators is ibopamine, an orally active dopamine agonist. Its haemodynamic effects are primarily due to peripheral vasodilation by activating dopamine receptors. ${ }^{54}$ Also, this drug has neurohumoral inhibiting effects, as it reduces plasma noradrenaline, and to a lesser extent, plasma aldosterone and renin. ${ }^{34}{ }^{55}$ In a recent placebo controlled study in patients with chronic heart failure, ibopamine partly prevented the deterioration of $H R$ variability found in the placebo group. This paralleled the mild neurohumoral effects of ibopamine. ${ }^{53}$

By contrast with drugs that inhibit neurohumoral activation in heart failure, as discussed earlier, other drugs do not affect or even enhance neurohumoral activation, including calcium channel blockers, diuretics, positive inotropic agents and antiarrhythmic drugs.

\section{CALCIUM CHANNEL BLOCKERS}

The use of calcium channel blockers in LV dysfunction and chronic heart failure is still controversial. Apart from small reports in patients with primarily diastolic dysfunction, ${ }^{56}$ so far there are no long-term studies that show positive results. Negative findings have been primarily attributed to the negative inotropic effects of calcium channel blockers and their ability to increase or at least not inhibit neurohumoral activation. ${ }^{57}$ Cook et al could not show any effect of diltiazem on HR variability in normal subjects. ${ }^{58}$ After myocardial infarction, however, diltiazem was found to reduce low frequency power. ${ }^{59}$ To our knowledge, there are no long-term data on the effects of calcium channel blockers on HR variability in patients with heart failure.

\section{DIURETICS}

Diuretics are effective in the treatment of acute heart failure, by reducing volume overload. Paradoxically in this condition, diuretics may be able to inhibit neurohumoral activation. ${ }^{60}$ In chronic heart failure, however, neurohumoral activity is less pronounced, and diuretics may in fact further stimulate neurohumoral activity, particularly the reninangiotensin system. ${ }^{61}$ Whether this also leads to untoward effects on $\mathrm{HR}$ variability during chronic treatment has not been reported so far.

\section{POSITIVE INOTROPIC AGENTS}

Positive inotropic agents such as $\beta$ adrenergic agonists and phosphodiesterase inhibitors without calcium sensitising properties, improved haemodynamics in heart failure, but were disappointing in long-term treatment. ${ }^{62}$ This may be related to an aggravation of arrhythmias, but also to other factorsfor example, increasing neurohumoral activation. ${ }^{36}$ Effects of these drugs on $\mathrm{HR}$ variability have not been published so far.

\section{ANTIARRHYTHMIC DRUGS}

Antiarrhythmic drugs (class I and III) have generally been found to be of limited value in patients with LV dysfunction and heart failure. Whereas the aim of treatment is to prevent arrhythmic events, proarrhythmic effects are often found in patients with a reduced LV function, partly because of their negative inotropic effects. Effects of antiarrhythmic 
drugs on $H R$ variability may not only be the result of the effects on the autonomic nervous system, but also of a direct effect on sinus node function. The effects of amiodarone (class III) ${ }^{63}$ and some class I agents on HR variability have been studied. ${ }^{63}{ }^{64}$ Zuanetti et al reported that amiodarone did not affect vagal activity, whereas both flecainide and propafenone caused significant decreases $(-56 \%$ and $-64 \%$ respectively).

\section{Summary}

Measures of heart rate variability correlate with the degree of neurohumoral activation in patients with LV dysfunction or heart failure. Because a significant correlation is present, analysis of HR variability also provides information on prognosis of these patients. Furthermore, HR variability may be used to predict LV dilatation after myocardial infarction, which is a strong independent risk factor. This indicates that before adverse haemodynamic changes have developed, changes in HR variability are already present. Variability in HR is indeed more closely correlated with neurohumoral activation than with haemodynamic variables, and as neurohumoral activation is disturbed earlier than the haemodynamic variables in heart failure, HR variability may be an early marker of progression of disease or loss of effect of treatment.

An important issue is the finding that drugs that inhibit neurohumoral activation in general seem to improve HR variability. By contrast, drugs that stimulate neurohumoral activation seem to have an adverse effect on $H R$ variability. Interestingly, this division into two groups also seems to be consistent with the long-term value of drugs in chronic heart failure. The relations between drug induced neurohumoral modulation, changes in HR variability, and prognosis in patients with $\mathrm{LV}$ dysfunction or heart failure need more attention. Restoration of the modulating properties of the autonomic nervous system in patients with chronic heart failure should be an important aim of treatment, which may contribute to improved survival.

1 Akselrod S, Gordon D, Madwed JB, Snidman NC Shannon DC, Cohen RJ. Hemodynamic regulation: investigation by spectral analysis. Am f Physiol 1985 249:H867-75

2 Francis GS, Goldsmith SR, Levine TB. The neurohumoral axis in congestive heart failure. Ann Intern Med 1984;101:370-7.

3 Tuininga YS, Crijns HJGM, Wiesfeld ACP, van Veldhuisen DJ, Hillege HL, Lie KI. Electrocardiographic patterns relative to initiating mechanisms of exercise-induced ventricular tachycardia.. Am Heart $\mathcal{f}$ 1993;126:359-67.

4 Podrid PJ, Fuchs T, Candinas R. Role of the sympathetic nervous system in the genesis of ventricular arrhythmias. Circulation 1990;82(suppl I):I103-13.

5 Lown B, Verrier R. Neural activity and ventricular fibrillation. N Engl ₹ Med 1976;294:1165-70.

6 Åblad B, Bjurö T, Björkman JA, Edström T, Olsson G. Role of central nervous beta-adrenoceptors in the prevention of ventricular fibrillation through augmentation
of cardiac vagal tone [abstract]. $\mathcal{f} \mathrm{Am}$ Coll Cardiol 1991;17:165A

7 Schwartz PJ, Vanoli E, Stramba-Badiale M, De Ferrari GM, Billman GE, Foreman RD. Autonomic mechanisms and sudden death: New insights from the analysis of baroreceptor reflexes in conscious dogs with and without myocardial infarction. Circulation 1988;78 969-79.

8 Maliani A, Pagani M, Lombardi F, Cerutti S. Cardiovascular neural regulation explored in the frequency domain. Circulation 1991;84:482-92.

9 Van den Broek SAJ, van Veldhuisen DJ, de Graeff PA, Crijns HJGM, van Gilst WH, Hillege HL, Lie KI. Mode of death in patients with congestive heart failure: comparison between possible candidates for heart transplantation and patients with less advanced disease. $\mathcal{f}$ plantation and patients with less adv
Heart Lung Transplant 1993;12:367-71.

10 Stevenson WG, Stevenson LW, Middlekauff HR, Saxon LA. Sudden death prevention in patients with advanced ventricular dysfunction. Circulation 1993;88:2953-61.

11 Sayers BM. Analysis of heart rate variability. Ergonomics 1973;16:17-32.

12 Van Ravenswaaij-Arts CMA, Kollee LAA, Hopman JCW, Stoelinga GBA, Van Geijn HP. Heart rate variability. Ann Intern Med 1993;118:436-47.

13 Cripps TR, Malik M, Farrell TG, Camm AJ. Prognostic value of reduced heart rate variability after myocardial infarction: clinical evaluation of a new analysis method. Br Heart $₹$ 1991;65:14-9.

14 Wolf MM, Varigos GA, Hunt D, Sloman JG. Sinus arrhythmia in acute myocardial infarction. Med $f$ Aust $1978 ; 2: 52-3$.

15 Kleiger RE, Miller JP, Bigger JT, Moss AJ. Decreased heart rate variability and its association with increased mortality after acute myocardial infarction. $\mathrm{Am} \mathcal{F}$ Cardiol 1987;59:256-62.

16 Bigger JT, Fleiss JL, Rolnitzky LM, Steinman RC, Schneider WJ. Time course of heart period variability after myocardial infarction. $₹$ Am Coll Cardiol 1991;18: 1643-9.

17 Pipilis A, Flather M, Ormerod O, Sleight P. Heart rate variability in acute myocardial infarction and its association with infarct size and clinical course. Am $¥$ Cardiol 1991;67:1137-9.

18 Farrell TG, Bashir Y, Cripps T, Malik M, Poliniecki J, Bennett ED, et al. Risk stratification for arrhythmic events in postinfarction patients based on heart rate variability, ambulatory electrocardiographic variable and the signal-averaged electrocardiogram. If Am Coll Cardiol 1991;18:687-97.

19 McAlpine HM, Morton Jj, Leckie B, Rumley A, Gillen G, Dargie HJ. Neuroendocrine activation after acute myocardial infarction. $\mathrm{Br}$ Heart $\mathcal{F}$ 1988;60:117-24.

20 Kingma JH, van Gilst WH, Peels CH, Dambrink JHE, Verheugt FWA, Wielinga RP, for the CATS investigators. Acute intervention with captopril during thrombolysis in patients with first anterior myocardial infarction. Eur Heart $f$ 1994;15:898-907.

21 Dambrink JHE, Tuininga YS, van Gilst WH, Kingma JH Left ventricular dilatation predicted by reduced heart Left ventricular dilatation predicted by reduced heart rate variability in survivors of a first a

22 Tuininga YS, Dambrink JHE, Kingma JH, van Gilst WH. Left ventricular dilation after a first anterior myocardial infarction and the course of recovery of heart rate variability [abstract]. Circulation 1993;88:1-473.

23 Saul JP, Arai Y, Berger RD, Lilly LS, Colucci WS, Cohen RJ. Assessment of autonomic regulation in chronic congestive heart failure by heart rate spectral analysis. $A m \mathcal{F}$ Cardiol 1988;61:1292-9.

24 Casolo G, Balli E, Taddei T, Amuhasi J, Gori C. Decreased spontaneous heart rate variability in congestive heart failure. $A m$ f Cardiol 1989;64:1162-7.

25 Binkley PF, Nunziata E, Haas GJ, Nelson SD, Cody RJ Parasympathetic withdrawal is an integral component of autonomic imbalance in congestive heart failure: autonomic imbalance in congestive heart failure: demonstration in human subjects and verification in a paced canine model of ventricular failure. $7 \mathrm{Am}$ Coll Cardiol 1991;18:464-72.

26 Kienzle MG, Ferguson DW, Birkett CL, Myers GA, Berg WJ, Mariano DI. Clinical, hemodynamic and sympathetic neural correlates of heart rate variability in congestive heart failure. Am $\mathcal{F}$ Cardiol 1992;69:761-7.

27 Brouwer J, Van Veldhuisen DJ, Man in ' $t$ Veld AJ, Dunselman PHJM, Haaksma J, Lie KI. Circadian pattern of heart rate variability in heart failure is progressively disturbed with increasing neurohormonal activation [abstract]. $\mathcal{f}$ Am Coll Cardiol 1994;(suppl A): activation.

28 Tuininga YS, Van Veldhuisen DJ, Crijns HJGM, Van den $\mathbb{D}$ Broek SAJ, Brouwer J, Haaksma J, et al. An exploratory Broek SAJ, Brouwer J, Haaksma J, et al. An exploratory study on the effects of single doses of isomazole on hemodynamics and heart rate variability in chron

29 Binder T, Frey B, Porenta G, Heinz G, Wutte M, Kreiner $\mathrm{G}$, et al. Prognostic value of heart rate variability in patients awaiting cardiac transplantation. PACE 1993; 15:2215-20.

30 Woo MA, Moser DK, Stevenson WG. Relationship of heart rate variability to sudden death in advanced heart 8 failure patients [abstract]. Circulation 1993;88:1-14.

31 Packer M. The neurohormonal hypothesis: a theory to explain the mechanism of disease progression in heart 6 explain the mechanism of $1992 ; 20: 248-54$

32 Swedberg $K$, Eneroth $P$, Kiekshus J, Wilhelmsen $L$. Horg Hormones regulating cardiovascular function in patients with severe congestive heart failure and

33 Nemanich JW, Veith RC, Abrass IB, Stratton JR. Effects 
of metoprolol on rest and exercise cardiac function and plasma catecholamines in chronic congestive heart failure secondary to ischemic or idiopathic cardiomyopathy. Am 7 Cardiol 1990;66:843-8.

34 Van Veldhuisen DJ, Man in 't Veld AJ, Dunselman PHJM, Lok DJA, Dohmen HJM, Poortemans JC, et al. Double-blind placebo-controlled study of ibopamine and digoxin in patients with mild to moderate heart and digoxin in patients with mild to moderate heart failure: results of the Dutch ibopam

35 Parameshwar J, Poole-Wilson PA. The role of calcium antagonists in the treatment of chronic heart failure. Eur Heart 7 1993;13(suppl A):38-44.

36 Uretsky BF, Lawless CE, Verbalis JG, Valdes AM, Kolesar JA, Reddy PS. Combined therapy with dobutamine and amrinone in severe heart failure. Improved hemodynamics and increased activation of the reninangiotensin system with combined intravenous therapy. Chest 1987;92:657-62.

37 Peters RW, Mitchell LB, Brooks MM, Echt DS, Barker AH, Capone R, et al, for the CAST investigators.
Circadian pattern of arrhythmic death in patients receivCircadian pattern of arrhythmic death in patients receiv-
ing encainide, flecainide or moricizine in the cardiac ing encainide, flecainide or moricizine in the cardiac arrhythmia supp

38 Armstrong PW, Moe GW. Medical advances in the treatment of congestive heart failure. Circulation 1994;88: 2941-52.

39 Swedberg K, Eneroth P, Kjekshus J, Wilhelmsen L. Hormones regulating cardiovascular function in patients with severe congestive heart failure and their relation to mortality. Circulation 1990;82:1730-6.

40 Cohn JN, Francis GS, Simon AB, Johnson G. Response of plasma norepinephrine to long-term administration of failure: V-HeFT II. $₹ \mathrm{Am}$ Coll Cardiol 1992;19(suppl failure: $\mathrm{V}$

41 Flapan AD, Nolan J, Neilson JMM, Ewing DJ. Effect of captopril on parasympathetic activity in chronic cardiac failure secondary to coronary artery disease. $\mathrm{Am} \mathcal{\jmath}$ Cardiol 1992;69:532-5.

42 Binkley PF, Haas GJ, Starling RC, Nunziata E, Hatton PA, Leier CV, Cody RJ. Sustained augmentation of parasympathetic tone with angiotensin-converting enzyme-inhibition in patients with congestive heart failure. F Am Coll Cardiol 1993;21:655-61.

43 Kaufman ES, Bosner MS, Bigger JT, Stein PK, Kleiger RE, Rolnitzky LM, et al. Effects of digoxin and enalapril RE, Rolnitzky LM, et al. Effects of digoxin and enalapril on heart period variability and response to head
in normal subjects. Am 7 Cardiol 1993;72:95-9.

44 Waagstein F, Bristow MR, Swedberg K, Camerini F, Fowler MB, Silver MA, et al, for the Metroprolol in Dilated Cardiomyopathy (MDC) Trial Study Group. Beneficial effects of metoprolol in idiopathic dilated cardiomyopathy. Lancet 1993;342:1441-6.

45 Molgaard H, Mickley H, Pless P, Bjerregaard P, Moller $M$. Effects of metoprolol on heart rate variability in survivors of acute myocardial infarction. $\mathrm{Am} \neq \mathrm{F}$ Cardiol 1993;71:1357-9.

46 Coumel P, Hermida JS, Wennerblöm B, Leenhardt A, Maison-Blanch P, Cauchemez B. Heart rate variability in left ven-Blanch $P$, Cauchemez $B$. Heart rate variability in left ventricular hypertrophy and heart failure, and the

47 Jaeschke R, Oxman AD, Guyatt GH. To what extent do congestive heart failure patients in sinus rhythm benefit from digoxin therapy. A systematic overview and metaanalysis. Am $\mathcal{F}$ Med 1990;88:279-86.

48 Uretsky BF, Young JB, Shahidi FE, Yellen LG, Harrison MC, Jolly MK. Randomized study assessing the effect of digoxin withdrawal in patients with mild to moderate chronic heart failure: results of the PROVED trial. $7 A m$ Coll Cardiol 1993;22:955-62.
49 Packer $M$, Gheorgiade $M$, Young JB, Smith LK, Costantini PJ, Adams KF, et al, on behalf of the RADIANCE study. Randomized, double-blind, placebocontrolled, withdrawal study of digoxin in patients with chronic heart failure treated with converting-enzyme inhibitors [abstract]. f Am Coll Cardiol 1992;19(suppl A):260A.

50 Gheorgiade $M$, Ferguson D. Digoxin. A neuromodulator in heart failure? Circulation 1991;84:2181-6.

51 Gillis RA, Pearle DL, Levitt B. Digitalis: a neuroexcitatory drug. Circulation 1975;52:739-42.

52 Ferguson DW, Berg WJ, Sanders JS, Roach PJ, Kempf JS, Kienzle MG. Sympathoinhibitory responses to digitalis glycosides in heart failure patients; direct evidence from sympathetic neural recordings. Circulation 1989;80: 65-77.

53 Brouwer J, van Veldhuisen DJ, Man in 't Veld AJ, Haaksma J, Viersma JW. Relation between heart rate variability and neuro variability and nith heart failure. Effects of neurohumoral modulation by
digoxin and ibopamine [abstract]. Circulation 1993;88: digoxin

54 Rousseau MF, Raigoso J, Van Eyll C, Van Mechelen $\mathrm{H}$, Musso NR, Lotti G, Pouleur H. Effects of intravenous epinine administration on left ventricular systolic performance, coronary hemodynamics, and circulating catecholamines in patients with heart failure. $\mathcal{f}$ Cardiovasc Pharmacol 1992;19:155-62.

55 Missale C, Metra M, Sigala S, Memo M, Dei Cas L, Spano PF. Inhibition of aldosterone secretion by dopamine, ibopamine, and dihydroergotoxine in patients with congestive heart failure. $\mathscr{f}$ Cardiovasc Pharmacol 1989;14(suppl 8):72-6.

56 Setaro JF, Zaret BL, Schulman DS, Black HR, Soufer R Usefulness of verapamil for congestive heart failure associated with abnormal left ventricular diastolic filling and normal left ventricular systolic performance. $A m \mathcal{F}$ and normal left ventric

57 Packer M. Pathophysiological mechanisms underlying the adverse effects of calcium channel-blocking drugs in patients with chronic heart failure. Circulation 1989; 80(suppl IV):59-67.

58 Cook JR, Bigger JT, Kleiger RE, Fleiss JL, Steinman RC, Rolnitzky LM. Effect of atenolol and diltiazem on heart 1991;17:480-4.

59 Bekheit S, Tangella M, El-Sakr A, Rasheed Q, Craelius $\mathrm{W}$, El-Sherif N. Use of heart rate spectral analysis to study the effects of calcium channel blockers on symstudy the effects of calcium channely after myocardial infarction. Am Heart $\mathcal{f}$ pathetic activity

60 Broqvist $M$, Dahlström U, Karlberg BE, Karlsson E, Marklund $T$. Neuroendocrine response in acute heart failure and the influence of treatment. Eur Heart $\mathcal{F}$ 1989;10:1075-83.

61 Bayliss J, Norell M, Canepa-Anson R, Sutton G, PooleWilson $P$. Untreated heart failure: clinical and neuroendocrine effects of introducing diuretics. Br Heart $f$ 1987;57:17-22.

62 Packer M, Varver JR, Rodeheffer RJ, Ivanhoe RJ, DiBianco R, Zeldis SM, et al, for the PROMISE study Research Group. Effect of oral milrinone on mortality in severe chronic heart failure. $N$ Engl $f$ Med 1991;325: severe ch

63 Zuanetti G, Latini R, Neilson JMM, Schwartz PJ, Ewing DJ. Heart rate variability in patients with ventricular arrhythmias: effect of antiarrhythmic drugs. $\mathcal{f} \mathrm{Am} \mathrm{Coll}$ Cardiol 1991;17:604-612.

64 Lombardi F, Torzillo D, Sandrone G, Dalla Vecchia L, Cappiello E. Autonomic effects of antiarrhythmic drugs and their importance. Eur Heart $\mathcal{f} 1992 ; 13$ (suppl F) F38-43. 